\title{
Choosing an Optimal Size Range of Pneumatically ACTUATED LiNEAR MODULES FOR SPRAYER ROBOTS
}

\author{
Velizar Zaharinov, Ivo Malakov, Stilian Nikolov, \\ Reneta Dimitrova \& Grigor Stambolov
}
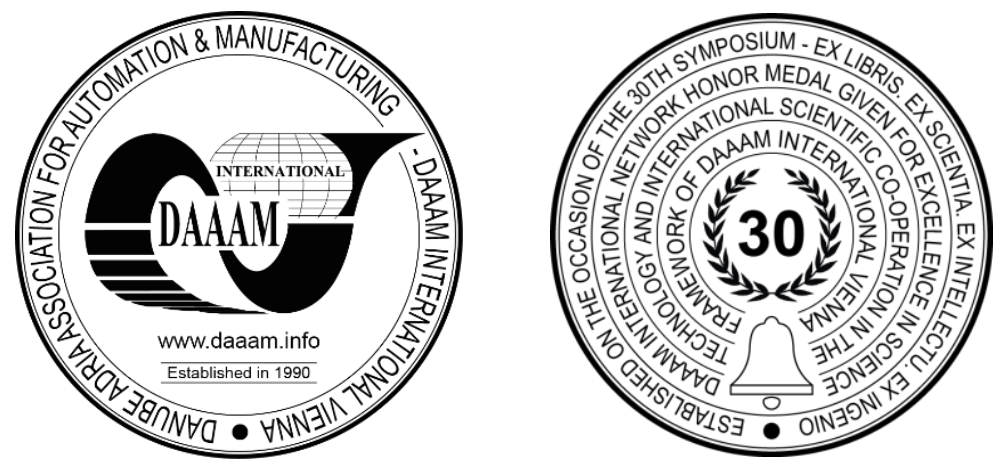

This Publication has to be referred as: Zaharinov, V[elizar]; Malakov, I[vo]; Nikolov, S[tilian]; Dimitrova, R[eneta] \& Stambolov, G[rigor] (2020). Choosing an Optimal Size Range of Pneumatically Actuated Linear Modules for Sprayer Robots, Proceedings of the 31st DAAAM International Symposium, pp.0159-0167, B. Katalinic (Ed.), Published by DAAAM International, ISBN 978-3-902734-29-7, ISSN 1726-9679, Vienna, Austria

DOI: $10.2507 / 31$ st.daaam.proceedings.021

\begin{abstract}
The paper presents results from the application of an approach for choosing an optimal size range of the product "Pneumatically actuated linear module". The application of the sizes in the size range is for realizing the vertical linear motion of die casting sprayer robots. The product is suitable for size range optimization, because each product type brings considerable production costs, and reducing the variety, and the related lowering of costs, would lead to a significant effect. A market research is carried out, an optimality criterion is chosen, and a mathematical model of the problem is proposed. The model accounts for a specific feature of the problem - each module can be applied only to a certain range of die casting machines built upon the locking force of the machine. On the basis of a known optimization method a recurrent dependency is used. The latter is used for calculation of the objective function, and in the application software used for solving the problem. The proposed approach is universal, and can be used for size range optimization of other products, after building the particular demand and costs models.
\end{abstract}

Keywords: optimization; size range; linear module; robot; die casting.

\section{Introduction}

A significant part of the building components used in the technical systems in mechanical engineering, electronics, electrical engineering, automotive industry, and other industry branches are produced in size (parametric) ranges, which are at the basis of the modular product [1], [2], [3], [4], [5], [6]. Significant investments are required for their design, production and operation, and their effectiveness relies largely on the elements that build the size ranges [7], [8], [9]. That is why, achieving good economic results for the manufacturers, as well as for the users, requires precise and scientifically sound determining of the included elements in the size ranges, and the values of their main parameters. To achieve this, it is necessary to solve the problem for choosing an optimal size range, which for minimum costs and/or maximum effectiveness (profit) in the fields of production and operation, has to completely satisfy certain product demand in terms of quantity [10]. This problem gains particular topicality in the current circumstances of strong competition, caused by the globalization in the world economy, as it significantly predetermines the marketing success of the manufactured products [3], [7]. 
The paper discusses a size range of pneumatically actuated linear modules. The elements of the size range are to be used for building die casting sprayer robots (Fig. 1) applicable to die casting machines with locking force in the range of 50 to 2500 tonnes. Sprayer robots are used for lubricating the dies in-between casting operations performed by die casting machines (for both hot and cold chamber die casting) in automated cells.

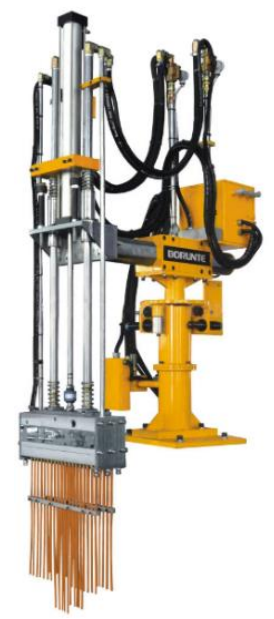

Fig. 1. Sprayer robot with pneumatically actuated linear vertical motion [11]

The elements of the size range are used for actuating the vertical linear motion of the die casting sprayer robot. At one end of the module a spraying head with nozzles is attached. The vertical linear motion lowers the spraying head in front of the dies, and after spraying, lifts the head back up, away from the closing dies.

Although, the product is not produced in very large series, it is, nevertheless, suitable for size range optimization, because each product type brings considerable production costs, and reducing the variety, and the related lowering of costs, would lead to a significant effect.

The size ranges of the pneumatically actuated linear modules used for the vertical motion of the robot sprayers, are closely related to the size ranges of the die casting machines offered on the market by the various manufacturers of cold and hot chamber die casting machines. The main parameter used for building the size range of the die casting machines is the locking force. Changing the locking force changes the machines dimensions, and so the required length of the vertical stroke of the sprayer robot changes, too.

There are size ranges of sprayer robots of different manufacturers offered on the market (SPESIMA, BORUNTE, Bühler, Wollin, Industrial Innovations, etc.), which are characterized by different number of sizes, application ranges, and different values of the main product parameters (Table 1).

\begin{tabular}{|c|c|c|c|c|}
\hline SPESIMA & BORUNTE & Bühler & Wollin & $\begin{array}{c}\text { Industrial } \\
\text { Innovations }\end{array}$ \\
\hline \multicolumn{5}{|c|}{ Application range (locking force), tonnes } \\
\hline $50-80$ & $130-180$ & 340 & $80-360$ & $250-400$ \\
\hline $80-315$ & $160-420$ & 530 & $160-360$ & $350-600$ \\
\hline $130-380$ & $280-420$ & $660-840$ & $360-560$ & $400-650$ \\
\hline $380-830$ & $500-850$ & $1050-1400$ & $560-750$ & \\
\hline $640-1050$ & 1250 & $1300-1400$ & $750-1000$ & \\
\hline $1050-2500$ & & $1600-1800$ & $1050-1250$ & \\
\hline & & $1600-2200$ & $1300-1600$ & \\
\hline
\end{tabular}

Table 1. Application ranges, with regard of the die casting machine locking force, of robot sprayers with vertical linear motion

The data in the table are according to the on-line catalogues of the companies and marketed products offered on the Internet and accessed in May 2020 [11], [12], [13], [14], [15]. The analysis of the specialized literature shows, that there is no information about the way the size ranges of the product are built, as it is know-how for the manufacturing companies, and they do not publish their research on the subject. Additionally, in known publications dealing with size ranges optimization [3], [9], [16], [17], [18], [19], the problem of products that are characterized with a certain application range is not solved. Such product becomes the pneumatically actuated linear module when used in the construction of sprayer robots, as each sprayer robot can be used for servicing die casting machines with a locking force corresponding to a certain range. Solving of the problem without taking into account of this application feature, leads to size ranges which include elements with too wide application ranges, that are not effective economically. 
The aim of the publication is to show the results from the application of a developed approach, methods and application software for size range optimization of the product "Pneumatically actuated linear module" when used for the vertical motion of sprayer robots.

\section{Size ranges optimization}

The choosing of an optimal size range is related to solving the problem [10]:

Determine the elements (the values of their main parameters) in a product size range, and the required quantity of each size range element. The size range must satisfy all demand with respect to type and quantity, and optimize a chosen objective function with given constraints.

Solving the so defined problem is carried out by an approach that consists of the following main stages [4]:

Stage 1. Choice of main parameters.

Stage 2. Determining demand.

Stage 3. Choice of optimality criterion.

Stage 4. Determining the functional relationship between the optimality criterion and the influencing factors.

Stage 5. Establishing a mathematical model.

Stage 6. Choice of a mathematical method.

Stage 7. Algorithmic and software development.

Stage 8. Solving the problem - choosing an optimal size range.

Stage 9. Sensitivity analysis of the optimal solution.

\subsection{Stage 1. Choice of main parameters}

Every product is characterized by a number of parameters, some of which are main (basic), and others - secondary (additional). The main parameters of the product determine the capability of executing a number of predetermined functions, and the secondary parameters are all the rest, that have secondary significance for the product, and do not define the product's ability to execute its appointed tasks.

The appropriate determining of the set of main parameters, in respect to which the optimization will be carried out, predetermines to a significant degree the effectiveness of the size ranges. The complexity and the amount of work needed for solving the optimization problem, depends on the choice of parameters, too.

For the product in question, one main parameter is chosen $\bar{x}_{l}-$ the stroke length of the pneumatically actuated linear module, as it determines the most important operational (functional) indicators of the product, it has stability, and does not depend on technical improvements, and production technology.

\begin{tabular}{|c|c|c|c|c|c|c|}
\hline $\begin{array}{c}\text { Module } \\
\text { size }\end{array}$ & $\begin{array}{c}\text { Stroke } \\
\text { length, } \mathrm{m}\end{array}$ & SPESIMA & BORUNTE & Bühler & Wollin & $\begin{array}{c}\text { Industrial } \\
\text { Innovations }\end{array}$ \\
\hline $\bar{x}_{1}$ & 0,650 & 0,650 & & & & \\
\hline $\bar{x}_{2}$ & 0,500 & & 0,500 & & & \\
\hline $\bar{x}_{3}$ & 0,610 & & & & & 0,610 \\
\hline $\bar{x}_{4}$ & 0,850 & & 0,850 & & & \\
\hline $\bar{x}_{5}$ & 0,700 & & 0,700 & & & \\
\hline $\bar{x}_{6}$ & 0,800 & 0,800 & & 0,800 & 0,800 & \\
\hline $\bar{x}_{7}$ & 0,900 & 0,900 & & & & \\
\hline $\bar{x}_{8}$ & 0,914 & & & & & 0,914 \\
\hline $\bar{x}_{9}$ & 1,000 & & & & 1,000 & \\
\hline $\bar{x}_{10}$ & 1,100 & & 1,100 & 1,100 & & \\
\hline $\bar{x}_{11}$ & 1,219 & & & & & 1,219 \\
\hline $\bar{x}_{12}$ & 1,250 & & 1,250 & & & \\
\hline $\bar{x}_{13}$ & 1,300 & 1,300 & 1,300 & & 1,300 & \\
\hline $\bar{x}_{14}$ & 1,200 & & & 1,200 & & \\
\hline $\bar{x}_{15}$ & 1,400 & & 1,400 & & & \\
\hline $\bar{x}_{16}$ & 1,500 & 1,500 & & & & \\
\hline $\bar{x}_{17}$ & 1,600 & & & 1,600 & 1,600 & \\
\hline $\bar{x}_{18}$ & 1,800 & & & 1,800 & & \\
\hline $\bar{x}_{19}$ & 1,900 & 1,900 & & & & \\
\hline $\bar{x}_{20}$ & 2,000 & & & 2,000 & 2,000 & \\
\hline
\end{tabular}

Table 2. Stroke lengths of the vertical linear motion of die casting sprayer robots 
In Table 2 are shown data for the nomenclature of pneumatically actuated linear modules' stroke lengths in the chosen application range of 50-2200 tonnes locking force, and the designations of the respective elements (sizes) of the modules' size range.

The stroke lengths correspond to the length of the vertical linear motion of sprayer robots offered on the market by the respective manufacturer. As it is evident from the table, in the range at hand there is a need of $\bar{L}=20$ module sizes, that build the initial size range $\bar{Z}=\left\{\bar{x}_{1}, \bar{x}_{2}, \ldots, \bar{x}_{l}, \ldots, \bar{x}_{\bar{L}}\right\}, l=1 \div \bar{L}$.

\subsection{Stage 2. Determining demand}

The demand for each module size included in the initial size range $\bar{Z}$ is determined after a market research, i.e. the elements of the set $\bar{N}=\left\{\bar{N}^{1}, \bar{N}^{2}, \ldots, \bar{N}^{l}, \ldots, \bar{N}^{\bar{L}}\right\}, l=1 \div \bar{L}$ are determined, where $\bar{N}^{l}$ is the quantity of the required products of size $\bar{x}_{l}$. The obtained results are shown in Fig. 2. The product's main parameter values are input along the abscissa - the stroke length of the module, and along the ordinate - the corresponding quantity.

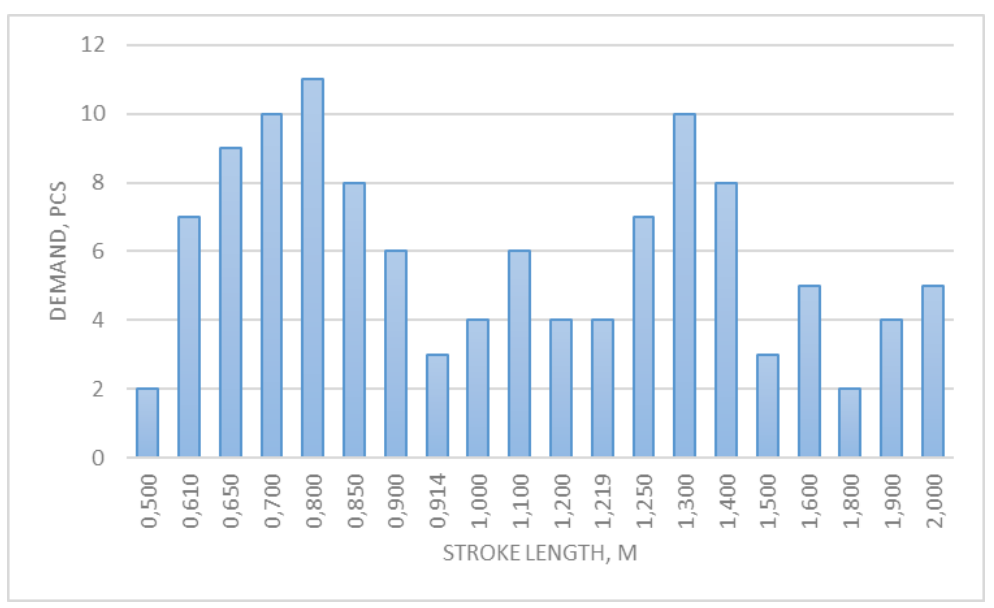

Fig. 2. Product demand from market research

\subsection{Stage 3. Choice of optimality criterion}

For solving the problem, the proposed optimality criterion is total costs for the size range, which have to be minimized. These costs include production costs, and operational costs. The proposed criterion takes into account the contradicting interests of users and manufacturers, and will lead to finding such size range, which is a compromise between the users' requirement for high size range density, that ensures fuller, more accurate, satisfaction of demand and reducing to a minimum the losses (the additional costs) from the discrepancy between supply and demand, and the manufacturers' requirement for size ranges with lower density, that aims for bigger batches and lowering the production costs.

Therefore, the chosen criterion for evaluation of the alternative size ranges, and for choosing an optimal size range, is of the following kind [4]:

$$
\mathrm{R}=\sum_{j=1}^{L} T S\left(x_{l_{j}}\right) N^{l_{j}}\left(\frac{N_{T S}}{N^{l_{j}}}\right)^{v_{1}}+\sum_{j=1}^{L} T P\left(x_{l_{j}}\right) N^{l_{j}}
$$

where $\mathrm{R}$ are the total costs for all elements in the size range; $L$ - the number of elements in the analysed size range; $x_{l_{j}}-$ the main parameter value of the $l_{j}$-th size in the current size range; TS $\left(x_{l_{j}}\right)$ - costs of producing the $l_{j}$-th size; TP $\left(x_{l_{j}}\right)$ - the operational costs for the $l_{j}$-th size; $N^{l_{j}}$ - the quantity (count) of the $j$-th product size, $N^{l_{j}} \in N=\left\{N^{l_{1}}, N^{l_{2}}, \ldots, N^{l_{L}}\right\}$, where $N$ is the set of product demand for the current size range; $v_{1}$ - the coefficient, describing the intensity of change in costs in relation to the change in the production quantity, taking into account the "learning rate" [20]; $N_{T S}-$ the coefficient that takes into account the production scale;.

\subsection{Stage 4. Determining the functional relationship between the optimality criterion and the influencing factors}

Determining the functional relationship between the optimality criterion and the influencing factors (parameters, coefficients) is carried out on the basis of production analysis, production cost data and operational costs data for the product "Pneumatically actuated linear module". The relationship for determining the total costs is obtained utilizing statistical methods for data analysis and regression analysis. It is the expression [21]: 


$$
\begin{aligned}
& \mathrm{R}=\sum_{j=1}^{L}\left[\left(10271,7+925,7 x_{l_{j}}+8,651\right)\left(\frac{9}{N^{j}}\right)^{0,25}+9304,32 x_{l_{j}}^{2}+77,47 \sqrt{30 x_{l_{j}}}+154,945 x_{l_{j}}+\right. \\
& +66,67] N^{j}+\left(4323,9+308,57 x_{l_{j}}+2,88\right)\left(\frac{9}{N^{j}}\right)^{0,25}
\end{aligned}
$$

The change in the total costs in relationship to the number of sizes in the size range is shown in Fig. 3 as a discrete function represented by a bar chart. Additionally, Fig. 3 shows a trend line (represented by a red curve) which is a continuous approximation (by moving average) of the discrete function. As it is can be seen from the figure, the objective function is a discrete convex function that has one global minimum. This property will be used for determining the condition for stopping the calculations according to a chosen optimization method.

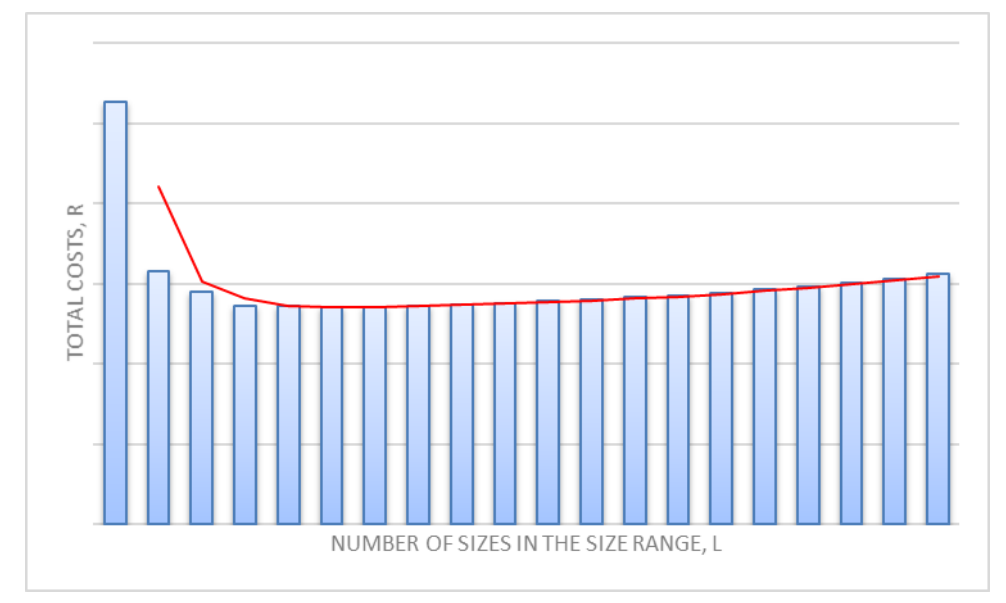

Fig. 3. Total costs as a function of the number of sizes in a size range

\subsection{Stage 5. Establishing a mathematical model}

The mathematical model of the problem for choosing an optimal size range is the following:

For a given demand $\bar{N}=\left\{\bar{N}^{1}, \bar{N}^{2}, \ldots, \bar{N}^{l}, \ldots, \bar{N}^{\bar{L}}\right\}, l=1 \div \bar{L}$, of products $\bar{Z}=\left\{\bar{x}_{1}, \bar{x}_{2}, \ldots, \bar{x}_{l}, \ldots, \bar{x}_{\bar{L}}\right\}, l=1 \div \bar{L}$, and the feasible possibilities for satisfying the different demands, i.e. the elements of the applicability matrix $\bar{\Phi}_{\bar{L} \times \bar{L}}=\left\|\varphi_{m}^{p}\right\|_{\bar{L} \times \bar{L}}$, find $L^{*}, Z^{*}=\left\{x_{l_{1}}^{*}, x_{l_{2}}^{*}, \ldots, x_{l_{j}}^{*}, \ldots, x_{l_{L^{*}}}^{*}\right\}, Z^{*} \subseteq \bar{Z}, j \in\{1,2, \ldots, \bar{L}\}, N^{*}=\left\{N^{* l_{1}}, N^{* l_{2}}, \ldots, N^{* l_{j}}, \ldots, N^{* l_{L^{*}}}\right\}, L^{*} \leq \bar{L}$, for which the chosen effectiveness (optimality) criterion must have minimal value:

$$
\operatorname{minR}=\left(L, \bar{x}_{1}, \ldots, \bar{x}_{l}, \ldots, \bar{x}_{\bar{L}}, \bar{N}^{1}, \ldots, \bar{N}^{l}, \ldots, \bar{N}^{\bar{L}}, \bar{\Phi}_{\bar{L} \times \bar{L}}\right)=\sum_{j=1}^{L} G\left\{x_{l_{j}}, N^{l_{j}}\left(\varphi_{m}^{p}, N^{p}\right)\right\}
$$

for the following conditions:

$$
\begin{aligned}
& \sum_{j=1}^{L} N^{l_{j}}=\sum_{j=1}^{L^{*}} N^{* l_{j}}=\sum_{j=1}^{\bar{L}} \bar{N}^{l}=N_{0} \\
& x_{l_{L}}=x_{l_{L^{*}}^{*}}^{*}=\bar{x}_{\bar{L}} \\
& x_{l_{j}} \in \bar{Z}=\left\{\bar{x}_{1}, \bar{x}_{2}, \ldots, \bar{x}_{l}, \ldots, \bar{x}_{\bar{L}}\right\}, \forall j=1 \div \bar{L}
\end{aligned}
$$

where $\bar{L}$ is the number of elements in the initial size range $\bar{Z}$, determined after demand research, $\operatorname{dim} \bar{Z}=\bar{L} ; L-$ the number of elements in the currently analyzed size range $Z=\left\{x_{l_{1}}, x_{l_{2}}, \ldots, x_{l_{j}}, \ldots, x_{l_{L}}\right\}, j \in\{1,2, \ldots, \bar{L}\}$. There is a unique representation between the elements of the current and initial size range, whereby each element $x_{l_{j}}$ corresponds to one element $\bar{x}_{m}$. The elements of the current size ranges are a combination of $L, L=1 \div \bar{L}$, elements of $\bar{L}$ number of possible elements of the initial size range taking into account the allowed application ranges; $L^{*}$ - the number of elements in the optimal size range $Z^{*} ; \bar{\Phi}_{\bar{L} \times \bar{L}}$ - applicability matrix, which elements give information about the allowable application ranges for the products in the initial size range $\bar{Z}$ that satisfy the demand $\bar{N}$, where $\varphi_{m}^{p}=1$ if the product from type $m$, $m=1 \div \bar{L}$, can satisfy the demand $\bar{N}^{p}$ of product $\bar{x}_{p}, p=1 \div \bar{L}$, and $\varphi_{m}^{p}=0$ otherwise; $N^{l}\left(\varphi_{m}^{p}, N^{p}\right)-$ the demand of product $x_{l_{j}}$ that is an element of the currently analyzed size range $Z$, whose index $l_{j}$ corresponds to the index $m$ of product 
$\bar{x}_{m} \in \bar{Z}$, element of the initial size range, as $x_{l_{j}}=\bar{x}_{m}$, where $N^{l_{j}}\left(\varphi_{m}^{p}, N^{p}\right)=\sum_{p=l_{j-1}}^{l_{j}} \varphi_{l_{j}}^{p} N^{p} ; N_{0}$ - total quantity of production of all elements in the size range.

Condition (4) means, that all analyzed size ranges, including the optimal, must satisfy all demand in terms of quantity, condition (5) means, that every size range, including the optimal, must include the element from the initial size range with the maximum value of its main parameter $\bar{x}_{\bar{L}}$, and condition (6), that the elements of all size ranges are chosen from the set of elements of the initial size range, determined after demand research. The demand set $\bar{N}$ is defined in tabular form and is determined in Stage 2. The values of the elements of the applicability matrix are determined by experts, on the basis of the data presented in Table 1 and 2. The values are shown in Fig. 4.

\begin{tabular}{|l|l|l|l|l|l|l|l|l|l|l|l|l|l|l|l|l|l|l|l|l|}
\hline & N1 & N2 & N3 & N4 & N5 & N6 & N7 & N8 & N9 & N10 & N11 & N12 & N13 & N14 & N15 & N16 & N17 & N18 & N19 & N20 \\
\hline $\mathrm{x} 1$ & 1 & & & & & & & & & & & & & & & & & & & \\
\hline $\mathrm{x} 2$ & & 1 & & & & & & & & & & & & & & & & & & \\
\hline $\mathrm{x} 3$ & & & 1 & & & & & & & & & & & & & & & & & \\
\hline $\mathrm{x} 4$ & & 1 & 1 & 1 & & & & & & & & & & & & & & & & \\
\hline $\mathrm{x} 5$ & & & & 1 & 1 & & & & & & & & & & & & & & & \\
\hline $\mathrm{x} 6$ & & 1 & 1 & 1 & 1 & 1 & & & & & & & & & & & & & & \\
\hline $\mathrm{x} 7$ & & & & & & 1 & 1 & & & & & & & & & & & & & \\
\hline $\mathrm{x} 8$ & & & & 1 & 1 & 1 & 1 & 1 & & & & & & & & & & & & \\
\hline $\mathrm{x} 9$ & & & & & & 1 & 1 & 1 & 1 & & & & & & & & & & & \\
\hline $\mathrm{x} 10$ & & & & & & & & 1 & 1 & 1 & & & & & & & & & & \\
\hline $\mathrm{x} 11$ & & & & & & & & 1 & 1 & 1 & 1 & & & & & & & & & \\
\hline $\mathrm{x} 12$ & & & & & & & & & 1 & 1 & 1 & 1 & & & & & & & & \\
\hline $\mathrm{x} 13$ & & & & & & & & & 1 & 1 & 1 & 1 & 1 & & & & & & & \\
\hline $\mathrm{x} 14$ & & & & & & & & & & & & & 1 & 1 & & & & & & \\
\hline $\mathrm{x} 15$ & & & & & & & & & & & & & & & 1 & & & & & \\
\hline $\mathrm{x} 16$ & & & & & & & & & & & 1 & 1 & 1 & 1 & 1 & 1 & & & & \\
\hline $\mathrm{x} 17$ & & & & & & & & & & & & & & & & 1 & 1 & & & \\
\hline $\mathrm{x} 18$ & & & & & & & & & & & & & & & & & & 1 & & \\
\hline $\mathrm{x} 19$ & & & & & & & & & & & & & & & & & & 1 & 1 \\
\hline $\mathrm{x} 20$ & & & & & & & & & & & & & & & & & & & 1 & 1 \\
\hline
\end{tabular}

Fig. 4. Applicability matrix

\subsection{Stage 6. Choice of a mathematical method}

The formulated problem for choosing an optimal size range belongs to the problem class of discrete programming. By its nature the problem refers to distribution problems, but differs from them by the presence of variable number of arguments, and variable values of the arguments, which complicates its solution. Additionally, the problem characterizes with large number of possible size ranges, that have to be analyzed [10].

This number, without taking into account the allowed applicable ranges of the discussed products, is determined from the expression $\sum_{k=1}^{\bar{L}-1} C_{\bar{L}-1}^{k}=2^{\bar{L}-1}-1$, where $k$ is the number of elements in the size range established from the elements of the initial size range with $\bar{L}-1$ elements [16]. For $\bar{L}-1=19$ it is necessary to process $2^{19}-1=524287$ different size ranges. That leads to a significant number of calculations, and imposes the use of a method for directed search of the optimal solution.

Furthermore, the method used must allow for respecting the application ranges of each product in the size range. This leads to lower number of variants, but complicates the finding of solution.

One of the efficient methods for solving of this class of problems is the dynamic programming method [22]. The method is based on the optimality principle of the American mathematician R. Bellman, stating: "the optimal strategy has a property such that no matter what is the initial state of the system in question, and the first stage solution, the following solutions (the solutions of the separate stages) must constitute an optimal strategy with respect to the state obtained as a result from the first solution".

On the basis of this principle the following recurrent dependencies for determining the total costs are obtained:

- for $l=1, m=l \div \bar{L}$,

$R_{m}^{1}=\frac{1}{\prod_{p=1}^{m} \varphi_{p}^{m}} \sum_{j=1}^{L} G\left\{x_{l_{j}}, N^{l_{j}}\left(\varphi_{m}^{p}, N^{p}\right)\right\}$

- for $l=2 \div \bar{L}, m=l \div \bar{L}, m^{\prime}=(l-1) \div(m-1)$, 


$$
R_{m}^{l}=\min \left\{R_{m^{\prime}}^{l-1}+\frac{1}{\prod_{p=m^{\prime}+1}^{m} \varphi_{p}^{m}} \sum_{j=1}^{L} G\left\{x_{l_{j}}, N^{l_{j}}\left(\varphi_{m}^{p}, N^{p}\right)\right\}\right\}
$$

where $R_{m}^{l}$ are the minimum total costs for satisfying demand for products with main parameter value $\bar{x}_{m}$ with number of $l$ sizes.

As the objective function is a discrete convex function, and has one global minimum, the calculation of $R_{m}^{l}, l=1 \div$ $\bar{L}$, continues, until the following condition is met:

$$
R_{\bar{L}}^{l} \leq R_{\bar{L}}^{l+1}
$$

\subsection{Stage 7. Algorithmic and software development}

An algorithm based on the proposed recurrent dependencies (7), (8), and condition (9) is developed for solving the problem. A software application is developed using the algorithm. The application uses as input Excel tables and writes the solution in the same format. The application is realized in the Python programming language.

\subsection{Stage 8. Solving the problem - choosing an optimal size range}

The problem (3)-(6) is solved with the aid of the developed tools (mathematical model of the optimization problem, cost models for production and operational costs, algorithm and application software).

The results are shown in Table 3, where $R^{*}$ are the minimum (optimal) total costs, $€ ; L^{*}$ - the number of elements in the optimal size range; $R_{\bar{L}}^{\bar{L}}$ - total costs for the size range that includes all sizes, e.g. the initial size range, $€$.

\begin{tabular}{|c|c|}
\hline Indicators & Optimal size range \\
\hline$R^{*}$ & 2531731,07 \\
\hline$L^{*}$ & 9 \\
\hline$R_{\bar{L}}^{\bar{L}}$ & 2796363,88 \\
\hline$\frac{R_{\bar{L}}^{\bar{L}}-R^{*}}{R_{\bar{L}}^{\bar{L}}}$ & $9,46 \%$ \\
\hline
\end{tabular}

Table 3. Results from solving the problem

The data for the chosen optimal size range are given in Table 4. It includes $L^{*}=9$ sizes.

\begin{tabular}{|c|c|c|c|}
\hline & $\begin{array}{c}\text { Size } \\
x_{l_{j}}^{*} \in X^{*}, j=1 \div 9\end{array}$ & $\begin{array}{c}\text { Size } \\
\bar{x}_{m} \in \bar{X}, l \in\{1, \ldots, \bar{L}\}\end{array}$ & Application range \\
\hline 1 & $x_{l_{1}}^{*}$ & $\bar{x}_{1}=0,65$ & $50-80$ \\
\hline 2 & $x_{l_{2}}^{*}$ & $\bar{x}_{6}=0,80$ & $180-360$ \\
\hline 3 & $x_{l_{3}}^{*}$ & $\bar{x}_{9}=1,00$ & $360-560$ \\
\hline 4 & $x_{l_{4}}^{*}$ & $\bar{x}_{12}=1,25$ & $560-650$ \\
\hline 5 & $x_{l_{5}}^{*}$ & $\bar{x}_{14}=1,20$ & $750-840$ \\
\hline 6 & $x_{l_{6}}^{*}$ & $\bar{x}_{15}=1,40$ & 1000 \\
\hline 7 & $x_{l_{7}}^{*}$ & $\bar{x}_{17}=1,60$ & $1050-1400$ \\
\hline 8 & $x_{l_{8}}^{*}$ & $\bar{x}_{19}=1,90$ & $1600-2200$ \\
\hline 9 & $x_{l_{9}}^{*}$ & $\bar{x}_{20}=2,00$ & $2200-2500$ \\
\hline
\end{tabular}

Table 4. Optimal size range

The production quantities of the elements in the optimal size range, and of the elements in the initial size range are shown in Fig. 5. The total costs, determined in the solving process as a discrete function, are shown in Fig. 6, with a polynomial of power 6 trend line approximation. Data regarding the size ranges of known companies with the same number of elements are given in Table 5.

The found optimal size range has the following features:

- reduces the number of sizes from 20 to 9 , i.e. with $45 \%$;

- reduces the total costs in comparison to the size range that includes all possible sizes with $281815,82 €$, i.e. with $9 \%$ 


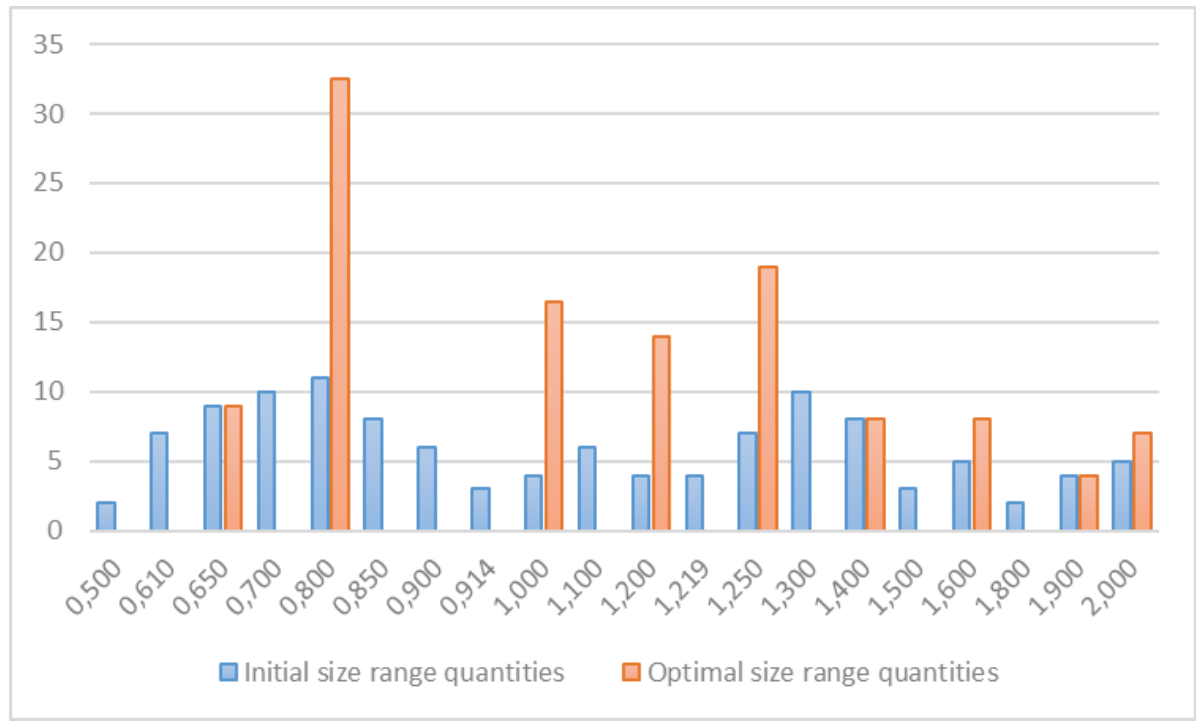

Fig. 5. Production quantity of the elements in the optimal size range

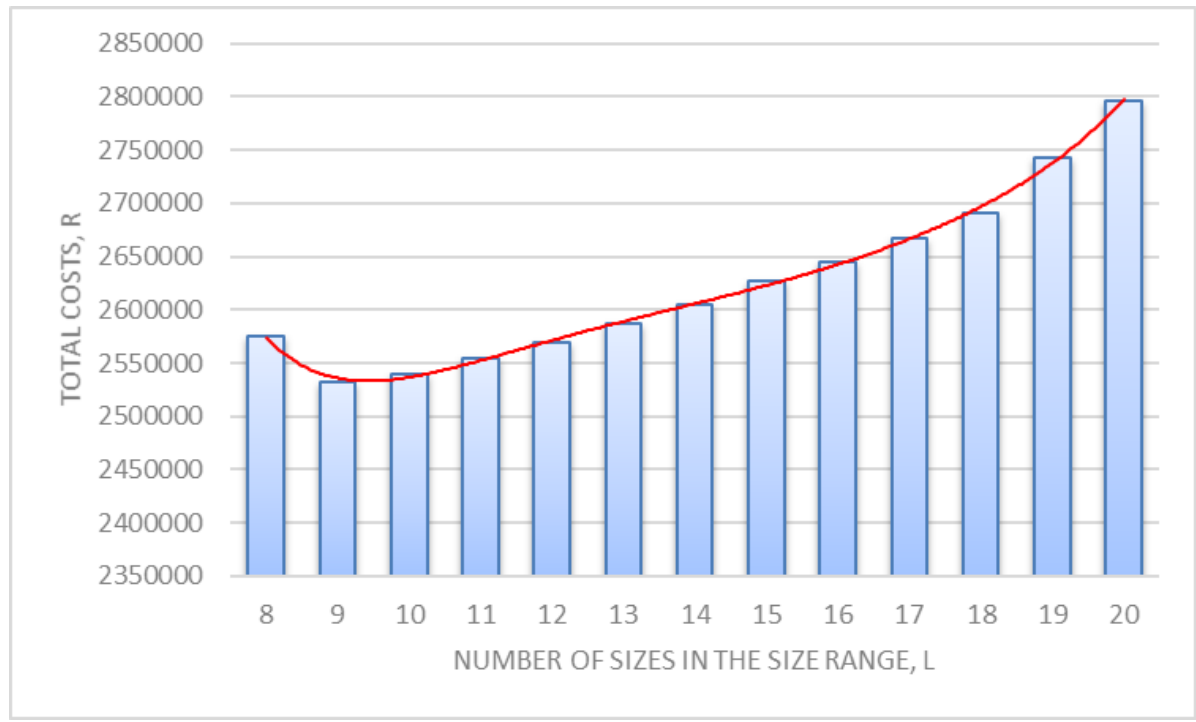

Fig. 6. Change in the total costs

\section{Conclusion}

The paper presents the size range optimization of the technical product "Pneumatically actuated linear module", which is characterized with a certain application range and is used as a modular component in die casting sprayer robots. The following important results are obtained:

- Main parameter of the product is chosen, and for it, an aggregate size range is built.

- The demand for the product "Pneumatically actuated linear module" is determined in relation to the vertical stroke length of die casting sprayer robots.

- The application ranges of the product are determined, in terms of the locking force of die casting machines, using market data of existing die casting sprayer robots.

- A mathematical model is used for the problem of choosing an optimal size range of a technical product with constraints over the applicability of the elements in the size range, and is adjusted for the product "Pneumatically actuated linear module".

- The functional dependency is determined between total costs and the influencing parameters through analysis of industry data.

- The optimal size range of the product "Pneumatically actuated linear module" is determined taking into account predetermined application ranges for the elements of the size range. The optimal size range reduces the number of sizes from 20 to 9 , i.e. with 55\%, reduces the total costs in comparison to the size range that includes all possible sizes with $9 \%$. 
The proposed approach has a universal nature, and can also be used for size range optimization of other products. Although, the optimization problem solved in the paper is with regard to a single parameter (the length of the linear modules), in practice there are problems that require the size range optimization with regard to more than one main parameter of the product. The development of an approach and tools used for solving of such problems is a natural continuation to the work presented here and subject to future work.

\section{Acknowledgments}

This work was supported by the European Regional Development Fund within the Operational Programme "Science and Education for Smart Growth 2014 - 2020" under the Project CoE "National center of mechatronics and clean technologies“ BG05M2OP001-1.001-0008

\section{References}

[1] Du, X., Jiao, J. \& Tseng, M.M. (2000) Architecture of product family for mass customization. Proc. 2000 IEEE International Conf. Management of Innovation and Technology, Singapore, Vol. 1, pp. 437-443

[2] Sand, J.C., Gu, P. \& Watson, G. (2002) Home: House of modular enhancement. A tool for modular product redesign. Concurrent Engineering: Research and Applications, 10(2), pp. 153-164

[3] Simpson, T. W. (2004) Product platform design and customization. Artificial Intelligence for Engineering Design, Analysis and Manufacturing, Cambridge University Press, 18, pp. 3-20

[4] Malakov, I. (2020) Optimization of size ranges of technical products for automation of the discrete production, D.Sc. Dissertation, Department "Automation of discrete production”, Technical university Sofia, Sofia, Bulgaria

[5] Zaharinov, V. \& Malakov, I. (2019). Determining the influence of model parameters on the choosing of an optimal size range of the product "Pipe clamp", Proceedings of the 30th DAAAM International Symposium, pp. 0324-0333, B. Katalinic (Ed.), Published by DAAAM International, ISBN 978-3-902734-22-8, ISSN 1726-9679, Vienna, Austria

[6] Andreev, V. (2019). Control System Mobile Robots with Modular Architecture as a Multi-Agent System with a Hierarchical Topology, Proceedings of the 30th DAAAM International Symposium, pp.0010-0019, B. Katalinic (Ed.), Published by DAAAM International, ISBN 978-3-902734-22-8, ISSN 1726-9679, Vienna, Austria

[7] Lotz, J., Freund, T., Würtenberger, J., \& Kloberdanz, H. (2015) Principles to develop size ranges of products with ergonomic requirements, using a robust design approach. 6th International Conference on Applied Human Factors and Ergonomics (AHFE 2015) and the Affiliated Conferences, pp. 1250-1257

[8] Malakov, I. (2015) Optimization of parametric ranges of technical products. (in Bulgarian) in: Complex automation of the discrete production, TU-Sofia, Sofia, pp. 25-48 ISBN 978-619-167-153-3

[9] Pahl, G., \& Beitz, W. (2007) Konstruktionslehre. Methoden und Anwendung. Berlin/Heidelberg, Springer-Verlag

[10] Malakov, I., Zaharinov, V., \& Tzenov, V. (2015) Size ranges optimization. Elsevier, Procedia Engineering, Volume 100, pp. 791-800

[11] BORUNTE Product Catalogue 2020, Vertical Sprayer, Guangdong BORUNTE Intelligent Equipment Co., Ltd.

[12] SPESIMA Brochure 2020, Bulgarisch-Deutsche Gesellschaft SPESIMA

[13] DC Brochure Carat 2020, Bühler

[14] PSM Die Spraying Machines 2020, Wollin GmbH

[15] Advance Automation Catalogue 2020, Industrial Innovations Inc.

[16] Dashenko, A.I., \& Belousov, A.P. (1983) Design of automated lines. (in Russian) Moscow, High School

[17] D'Souza, B., \& Simpson, T.W. (2003) A genetic algorithm based method for product family design optimization. Engineering Optimization, 35(1), pp.1-18

[18] Kipp, T., \& Krause, D. (2009) Computer aided size range development - data mining vs. optimization, in: Proceedings of ICED 09, Vol. 4, Product and Systems Design, Palo Alto, pp. 179-190

[19] Lotz, J. (2018) Beherrschung von Unsicherheit in der Baureihenentwicklung. Dissertation, Darmstadt

[20] Groover, M. (2001) Automation, Production Systems and Computer-Integrated Manufacturing, Second Edition, Prentice Hall ISBN: 9780130889782

[21] Malakov, I., \& Boyadjiev, I. (2001) Choice of optimal range of parameters of technical products, Annals of DAAAM for $2001 \&$ Proceedings of the 12th International DAAAM Symposium, ISBN 3-901509-19-4, Jena, Germany, 2427.10.2001, Published by DAAAM International, Vienna, Austria 2001, pp 285-286

[22] Bellman, R. (1957) Dynamic Programming. Princeton Univ. Press, New York 